\title{
Pittsburgh Meeting of the American Association
}

1 HE ninety-fifth meeting of the American Association for the Advancement of Science was held at Pittsburgh on December 27--January 2, and during the week members of this and associated organisations numbering nearly four thousand participated there in a most successful series of meetings. Joined with the eity as hosts were the Carnegie Institute of Technology, the University of Pittsburgh, the Pennsylvania College for Women, Duquesne University and the Mellon Institute. Dr. Thomas S. Baker, president of the Carnegie Institute of Technology, was chairman of the local committee and Dr. Davenport Hooker, of the University of Pittsburgh, vice-chairman. Arrangements for sessions were admirably provided in the group of academic and public buildings in the Schenley Park centre.

Two previous meetings have been held in Pittsburgh, both of them marked by events of especial significance in the history of the Association. The first in June 1902 was the last of the fifty-one summer meetings; at it was adopted a new plan for midwinter Convocation Week meetings, bringing together a large group of scientific organisations, the first of which was held in Washington in the following December. This plan, which has been followed ever since, has served well to develop scientific work and influence in the country. The second Pittsburgh meeting was held in December 1917 with a programme devoted to national preparedness and effective participation in the War. It exercised an important influence on the country at this crucial period.

Pittsburgh played a prominent part in early colonial history. Its strategic location and the immense value of the natural resources of the region gave support to the later initial enterprises in manufacturing lines, and led to the development of mining and other industrial activities on the immense scale that characterises this region to-day. The secret of its success has been the application of science to the utilisation of natural resources. In consequence, it offers attractions to scientific organisations which were well utilised in planning and carrying out the programme of the meeting.

In all, forty-two affiliated societies met in conjunction with the fifteen sections of the Association. The programmes were replete with papers of striking value, and attendance was larger than for several years past. A few of the outstanding features may be mentioned briefly.

The evening general sessions were held in the Carnegie Music Hall. On December 27, President Thorndike presided and responded to the addresses of welcome from the city and the universities. The address was given by Dr. William A. White of the U.S. Public Health Service on "Man, the Great Integrator" ; it was illustrated by examples from the field of psychiatry showing the reciprocal relation of the world within and the world without; it demonstrated how psychiatry, like general science, has discarded many of the older traditional ways of thinking and as a result has discovered a new world of thought and knowledge of great significance to the understanding of man and to culture in general.

On December 28, Prof. E. A. Hooton of Harvard delivered the Sigma Xi address on "Homo sapiens, Whence and Whither". On December 29, Dr. Charles F. Kettering, director of General Motors Research, spoke on "Some Future Problems of Science and Engineering". On December 31 came the address of the retiring president of the Association, Dr. Henry Norris Russell of Princeton, on "The Atmospheres of the Planets" [see p. 219]. The Josiah Willard Gibbs lecture was given by Prof. Albert Einstein [see Natc Re, Jan. 19, p. 111].

Among special afternoon lectures was one to mark the quarter centennial of the discovery of the north pole. It was given on December 27 by Prof. Wm. $\mathrm{H}$. Hobbs of Michigan on "The Career of Admiral Peary, the Discoverer of the North Pole". Prof. H. H. Newman of Chicago delivered an illustrated address on December 28 on "Twins Reared Apart and the Nature-Nurture Problem". On December 28 also, W. R. Chapline of the U.S. Forest Service lectured on "Forestry fosters New Approaches to Watershed Conservation", describing with sound films researches of the U.S. Forest Service dealing with stream. flow and erosion problems on forest and range lands. On December 29, Prof. M. H. Liddell of Purdue spoke on "The Acoustics of the Auditory Spectrum", and was assisted by Prof. C. T. Knipp of Illinois, who demonstrated the Knipp singing tubes. On December 30, Dr. Phillips Thomas of the Research Department of Westinghouse, under the title "Ramblings in Research", gave a remarkable demonstration of recent discoveries not previously presented publicly.

The American Society of Naturalists in its annual symposium dealt with "Cytogenetic Evolutionary Processes and Their Bearing on Evolution Theory". Prof. A. F. Shull of Michigan took as the subject of the presidential address "Weismann and Haeckel: One Hundred Years".

The Committee on the Place of Science in Education presented programmes of invited papers at two sessions, and had a largely attended luncheon, after which Dr. E. L. Thorndike, president of the Association', spoke on "Psychology of Attitudes".

Many symposia and joint sessions were arranged by various sections and affiliated societies. In one, the Ecological Society of America with the Society of American Foresters included an invitation paper by Dr. R. Maclagan Gorrie on "The Work of the Forest Research Institute, Dehra Dun, India", illustrated by fine moving pictures. A symposium on science and the Press was largely attended [see p. 239].

The production of active immunity against poliomyelitis was reported in papers by Dr. Maurice Brodie of New York City and bý John A. Kolmer of Temple University, and a series of invited papers on sulphur-containing compounds in their relation to cancer, arthritis, muscular dystrophy and cystinuria were presented in two especially important symposia in the Section of Medical Sciences.

The twelfth annual American Association prize of one thousand dollars was unanimously awarded by the committee to Dr. Vern O. Knudson of the University of California at Los Angeles, for his paper entitled "The Absorption of Sound in Gases". Dr. Knudson has cleverly adapted methods employed in acoustics to the important domain of molecular interactions. Above a frequency of 4,000 cycles per 
second the attenuation due to the absorption of sound in oxygen is so rapid that it decreases to a millionth of its initial intensity in travelling a distance of $60 \mathrm{~m}$. In an atmosphere of oxygen the consonants of high frequency in speech sounds could scarcely be heard across an ordinary street. The absorption of sound in a room at high frequencies is more influenced by the humidity and temperature of the air than by the absorbing boundaries of the room or the audience. The 'acoustic transparency' of the air at any temperature and humidity can be calculated. A new technique is furnished for investigating not only the nature of molecular collisions but also the nature of the molecular forces involved.

The only foreign delegates present at the meeting were the representatives of the South African Association for the Advancement of Science and the Royal Society of South Africa; they were Prof. H. B. Fantham and Mrs. Fantham (Dr. Annie Porter), of McGill University, Montreal.

The new Committee on Organisation recommended that the Council promote the establishment of local branches, as long since provided for in the constitution. It was voted to encourage the formation of such branches under the direction of the general secretary. On application of a group of seventyfive persons such a branch was established at Lancaster, Pa., and steps taken to assist in the organisation of other places.

By the courtesy of the Mellon Institute, the annual science exhibition occupied an entire floor of the splendid new building of the Institute. The exhibits of the National Bureau of Standards on deuterium and its compounds from twenty-five co-operating laboratories, the Bartol Research Foundation exhibit of cosmic ray apparatus, and the Columbia University demonstration of the production of artificial radioactive substances stood out among a long series of unusual research exhibits for their truly remarkable character.

The addresses of the retiring vice-presidents, given at various times, included the following: Mathematics, Prof. Charles N. Moore of the University of Cincinnati, on "Mathematics and Science"; Physics, Dr. Clinton J. Davisson of the Bell Telephone Laboratories, New York City. on "Electron Optics"; Chemistry, Prof. Arthur B. Lamb of Harvard University, on "Crystallogenetic Adsorbents"; Astronomy. Dr. Vesto M. Slipher of Lowell Observatory, Flagstaff, Ariz., on "The Atmosphere of the Planets as Inferred from Their Spectra"; Geology and Geography, Dr. Rollin T. Chamberlin of the
University of Chicago, on "Certain Aspects of Geologic Classifications and Correlations ; Zoology, Dr. George L. Streeter of the Carnegie Institution, Baltimore, Md., on "The Education of an Anatomist" ; Botany, Dr. Karl M. Wiegand of Cornell University, on "A Taxonomist's Experience with Hybrids in the Wild" ; Anthropology, Dr. T. Wingate Todd of Western Reserve University, on "Anthropology and Growth"; Psychology, Dr. Walter R. Miles of Yale University, on "Training, Practice and Mental Longevity"; Education, Prof. Walter F. Dearborn of Harvard University, on "The Mental and Physical Growth of Public School Children"; Social and Economic Sciences, Prof. Wesley C. Mitchell of Columbia University, on "The Social Sciences and National Planning"; Engineering, Dr. Charles F. Kettering of the General Motors Corporation, Detroit, Mich., on "Some Future Problems of Science and Engineering"; Medical Sciences, Dr. Cyrus C. Sturgis of the University of Michigan, on "Review of Some of the More Recent Advances in the Study of Blood Diseases"; Agriculture, Dr. Albert R. Mann of Cornell University, on "The Agricultural Significance of State and National Planning".

The following officers were among those elected for the year 1935 : President, Prof. Karl T. Compton of Massachusetts Institute of Technology ; General Secretary, Prof. Otis W. Caldwell of Teachers College, Columbia University; Vice Presidents of the Sections : Prof. T. H. Hildebrandt of the University of Michigan (Mathematics); Dr. John T. Tate of the University of Minnesota (Physics); Prof. Moses Gomberg of the University of Michigan (Chemistry); Dr. H. R. Morgan of the U.S. Naval Observatory (Astronomy); Prof. Walter E. McCourt of Washington University (Geology and Geography); Dr. Oscar Riddle of the Station for Experimental Evolution, Cold Spring Harbor, N.Y. (Zoological Sciences); Prof. E. W. Sinnott of Columbia University (Botanical Sciences) ; N. C. Nelson of the American Museum of Natural History, New York City (Anthropology) ; Joseph Peterson of George Peabody College for Teachers, Nashville (Psychology); Shelby Harrison of Russell Sage Foundation, New York City (Social and Economic Sciences); Dr. George Sarton of Harvard University Library (Historical and Philological Sciences); H. N. Davis of Stevens Institute of Technology, Hoboken, N.J. (Engineering) ; Stanhope Bayne-Jones of Yale University Medica] School (Medical Sciences); H. K. Hayes of the University of Minnesota (Agriculture); Prof. F. B. Knight of the University of Iowa (Education).

HENRY B. WARD.

\section{Science and the Newspaper Press in the United States}

\footnotetext{
$\mathrm{O}$ $\mathrm{NE}$ of the leading features of the recent meeting of the American Association for the Advancement of Science held at Pittsburgh, Pennsylvania, was a symposium on the relation between science and the Press. Although within the past decade Press reports of scientific work have become far more satisfactory than formerly, and distrustfulness of the Press on the part of scientific men has been greatly reduced, certain difficulties still exist. The object of the symposium was to bring these difficulties frankly into the open, in the hope that recognition and subsequent discussion might lead to their eventual removal.
}

The speakers at this symposium were: Dr. Karl T. Compton, president of the Massachusetts Institute of Technology, who is president-elect of the American Association; Mr. David Dietz, science editor of the Scripps-Howard Newspapers, and president of the National Association of Science Writers, Cleveland, Ohio ; Mr. Robert D. Potter, Science Service, Washington, District of Columbia, speaking for the director, Mr. Watson Davis ; Dr. Edward R. Weidlein, director of the Mellon Institute for Industrial Research, Pittsburgh, Pennsylvania; Mr. William L. Laurence, science news editor, the New York Times, New York ; Dr. Benjamin C. Gruenberg, 